\title{
KTT In A Digital Age
}

Is technology going to change how we connect with farmers?

Michelle Linington BSc (Agr)

MSc Candidate

Advisor: Vern Osborne

University of Guelph 


\section{Biography: Who Am I}

- Masters Student - Department of Animal BioScience

- Studying communications and KTT within the Ontario Dairy Industry

- OAC 2014 Grad with a BSc (Agr.) in Honours Agriculture

- Work for a company creating customized Health and Safety plans for farmers

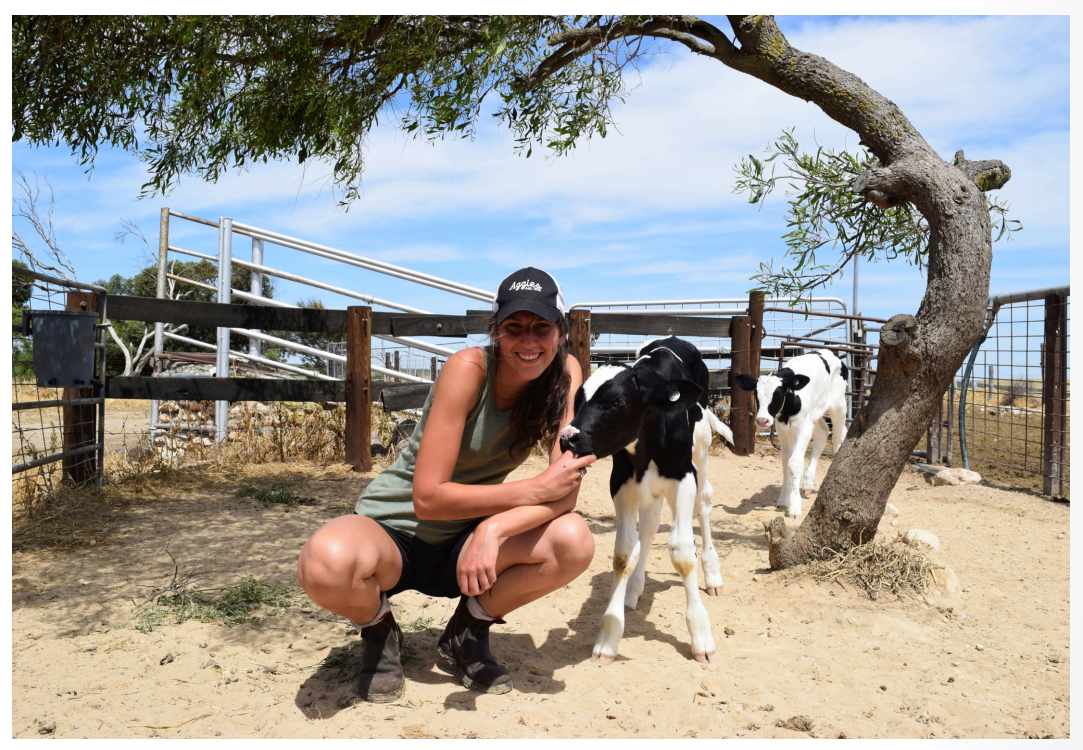




\section{The Changing Dairy Industry}

- Quickly becoming the most technologically advanced livestock industry within Ontario

- Change of focus to:

- Social license is a growing issue

- Equipment Advancements

- Moving away from small herds to larger herds

- Increasing demand for business skills and people management
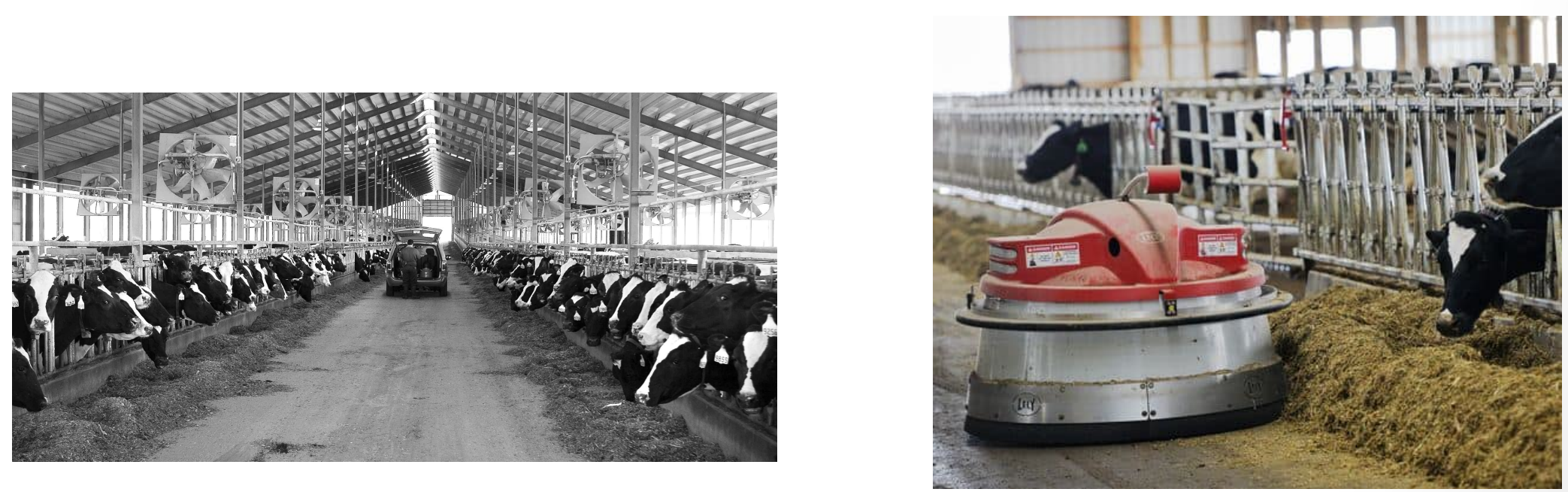
Do the changes in the industry mean we need to change how we talk to producers? 


\section{KTT and Dairy}

- Research directed at the dairy industry:

- Changing quickly

- Technologically advanced

- Motivated to see better managed

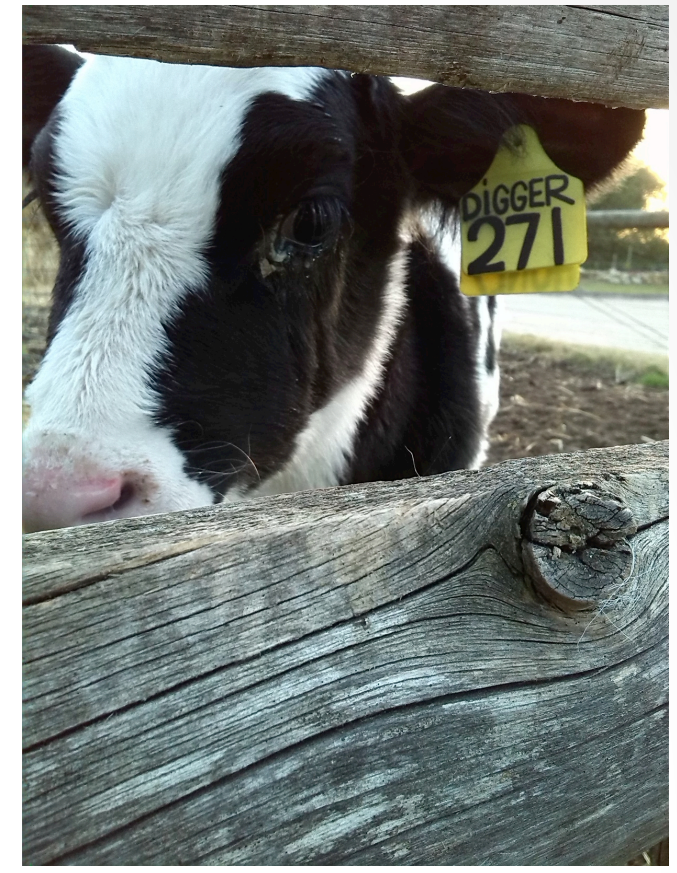

- Industry continues to be successful

- Focused on the current KTT system within Ontario and how the shift to a digital age has effected how we are communicating with our producers

- Industry needs are evolving therefore we need to adjust how we deliver information to producers to meet there needs 


\section{What is KTT Research About}

- Evaluated current state of KTT in Ontario

- Talked with representatives from:

- OMAFRA

- Swackhammer Vet Service

- Dairy Farmers of Ontario

- University of Guelph

- University of Kentucky (for comparisons)

- Compared several adult learning/personalities styles and types of Extension systems

- Looked at what makes for good extension

- The six things to consider when educating adults (Knowles,1970)

- The FAO Standards for extension and KTT (Swanson et al, 1997) 


\section{Closing the Gap}

- As a new generation comes into management we are finding the need to change how information is being distributed

- Digital technology is growing and changing faster than we can react

- Need to be proactive and adjust to the new 'standard'

- Social Media

- Video Conferences

- Traditional methods 


\section{Growing Agriculture Interest and Use of Social Media}

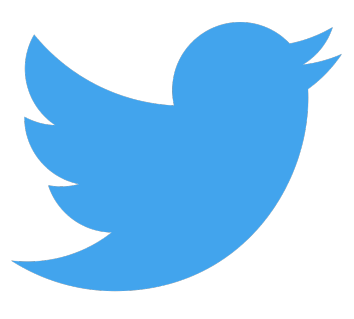

Andrew Campbell (Fresh Air Farmer) 19,900 followers

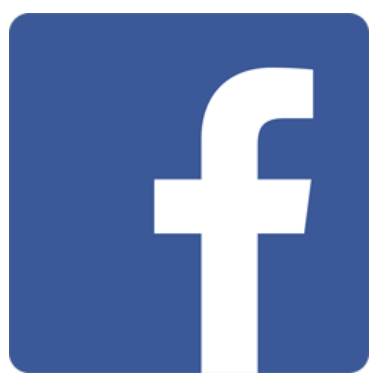

Cody Creelman (Vet) - 27,000 followers

\section{You Tube}


The End of the Gutenberg Era OROGERS.

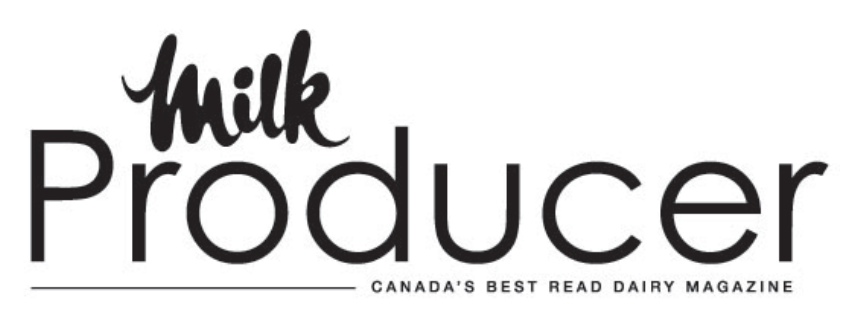

\#*IPROGRESSIVE DAIRYMAN 


\section{Why Go Digital?}

COST

- No handling fees

- No storing facilities

- No packing

- No mailing fees

Time
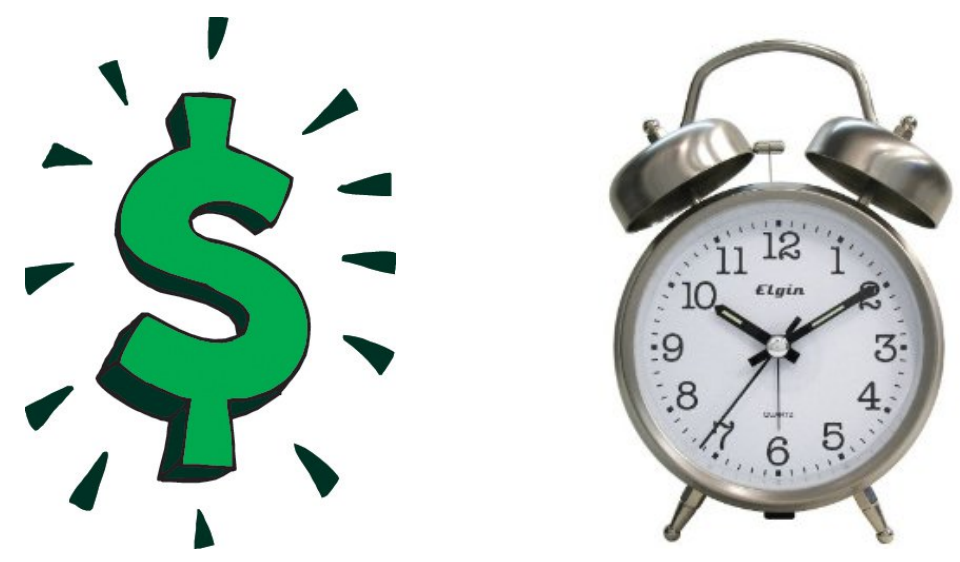

- Information gets in the hands of people faster

- Information on demand

Convenience

- Time of the farmer 


\section{BUT....}

One on one meetings are important... but not always needed 


\section{What does this mean?}

- Dairy producers still want a mix of communications:

- Digital

- This can be in a variety of forms

- Print

- Demo Days

- One to one meetings

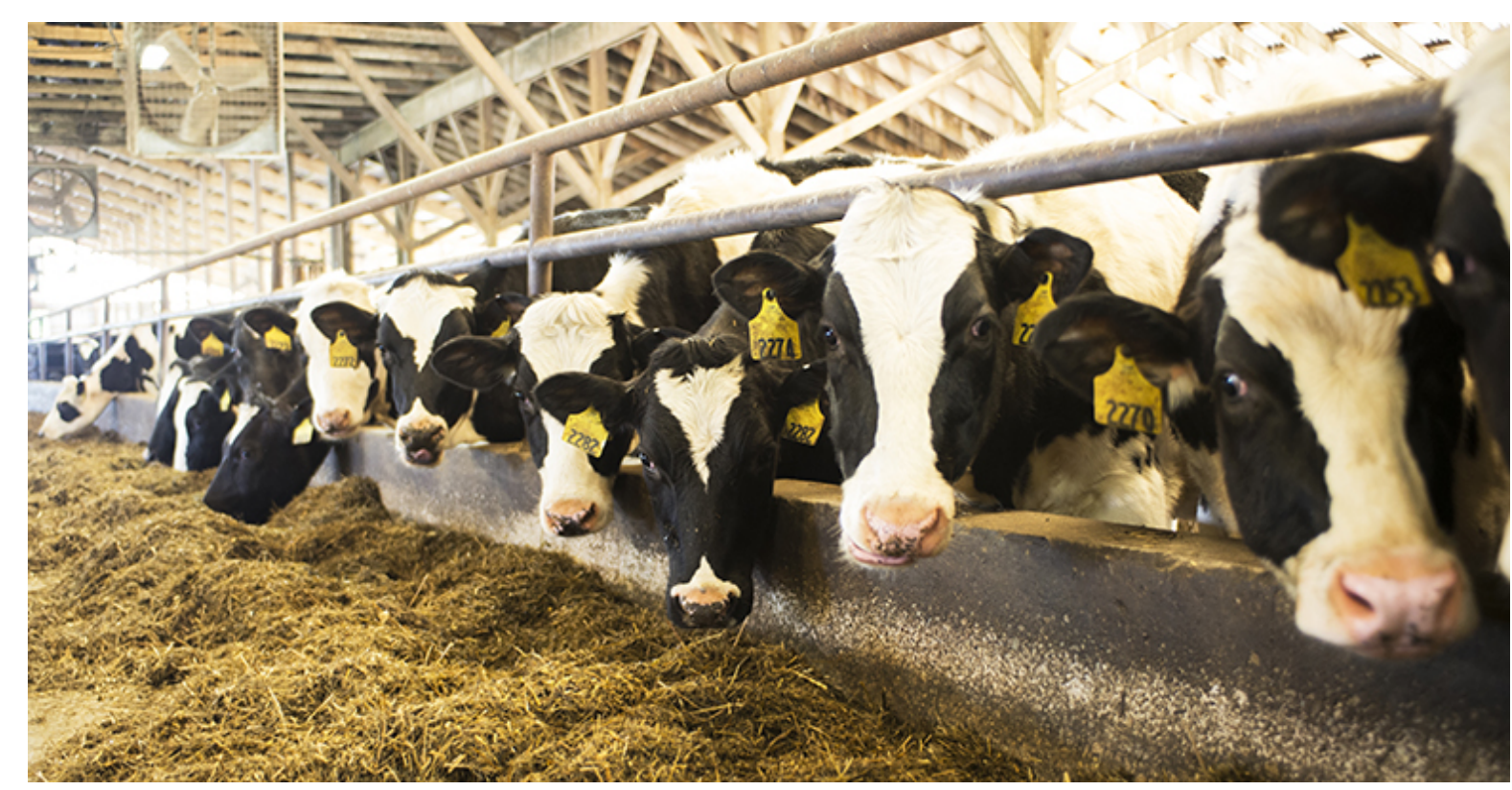




\section{Key Take Homes}

- Use a mix of platforms when delivering content

- Face to face meetings are more compelling, but expensive

- Use the available technology to redirect people to your online content

- Appreciate that we are going to become more digitally focused in content creation 